\title{
Vardenafil - A new and effective treatment for erectile dysfunction
}

\author{
Richard Casey MD FRCS Urology, Editor-in-Chief
}

R Casey. Vardenafil - A new and effective treatment for erectile dysfunction. J Sex Reprod Med 2003;3(4):128-132.

Vardenafil (Levitra, Bayer Healthcare/GlaxoSmithKline, USA) is a phosphodiesterase 5 inhibitor developed specifically for use as an oral therapy for erectile dysfunction (ED). This review provides an overview of recent clinical trial results that support the use of this compound as first-line therapy in patients with ED. Specifically, data from clinical trials performed in multiple countries have shown strong efficacy and good safety in the general population as well as in difficult-to-treat subpopulations, such as patients post bilateral nerve sparing radical prostatectomy and patients with diabetes mellitus. Furthermore, the features of a rapid onset of action, good reliability and increased patient satisfaction, while elements such as erection hardness and overall sexual experience may provide additional benefits to this particular patient group. Together with a good safety profile and minimal interactions with food and alcohol, it is clear that vardenafil offers a viable first-line treatment choice for men with ED.

Key Words: Cardiovascular safety; Clinical studies; Diabetes; Erectile dysfunction; Onset of action; Phosphodiesterase inhibitor; Prostatectomy; Reliability; Vardenafil

\section{Le vardénafil : un nouveau traitement efficace de la dysérection}

Le vardénafil (Levitra, Bayer Healthcare/GlaxoSmithKline, USA) est un inhibiteur de la phosphodiestérase 5 , spécialement conçu pour le traitement oral de la dysérection. La présente revue fait un survol des résultats des derniers essais cliniques qui étayent l'utilisation, en première intention, de ce composé. Plus précisément, les données provenant d'essais cliniques menés dans plusieurs pays montrent l'efficacité et l'innocuité du médicament dans la population en général ainsi que dans des sous-groupes de patients difficiles à traiter, comme ceux qui ont subi une prostatectomie radicale avec conservation nerveuse bilatérale et les diabétiques. De plus, la rapidité d'action du médicament et sa fiabilité, de même que la satisfaction accrue des patients à l'égard de certains points comme la rigidité de l'érection et la satisfaction sexuelle en général, peuvent ajouter au bien-fondé de l'utilisation du médicament dans ce groupe particulier de patients. Compte tenu de sa bonne marge d'innocuité et de son peu d'interactions avec la nourriture et l'alcool, il ne fait aucun doute que le vardénafil offre un nouveau traitement durable, de première intention, de la dysérection.
T is well known that erectile dysfunction (ED) has a substantial impact on patient quality of life; in particular, it impacts on men's self-esteem and their intimate relationships. With this in mind, it becomes even more important that the ED treatments developed are effective the first few times they are used, and continue to be effective over time. Local therapies, while effective, suffered due to the lack of spontaneity, or were invasive, painful or unappealing. The appearance of sildenafil revolutionized ED therapy. Oral phosphodiesterase 5 (PDE5) inhibitors have become the first treatment of choice for the management of ED. Sildenafil has been available since 1998, and has been shown to be efficacious and safe for the treatment of ED $(1,2)$. However, a high rate of dissatisfaction and discontinuation of treatment has been reported; only approximately 39\% of patients receiving sildenafil renewed their prescription after one year (3). In fact, discontinuation rates range from $14 \%$ to as high as $47 \%$. The most frequent reason cited for the discontinuation of sildenafil therapy is lack of efficacy. These results have been confirmed in an independent global survey evaluating men's attitudes towards life events and sexuality (MALES), conducted from February to April 2001 in 27,838 men aged 20 to 75 years (4). These findings demonstrate that there is an unmet need for new oral medications that will meet patient expectations of a reliable treatment.

\section{THERAPEUTIC EFFICACY}

The results of a number of large scale clinical trials have shown that vardenafil has strong efficacy and a favourable safety profile in the general population, as well as in harder-to-treat subpopulations such as patients post nerve-sparing radical prostatectomy (NSRP) and patients with diabetes mellitus (5-9). Most studies were of randomized, double-blind, multicentre, fixed-dose design, and of 12 or 26 weeks in duration, with one long term study extended to 104 weeks (10). There were no restrictions regarding food or alcohol consumption. Primary endpoints included the Erectile Function (EF) domain score of the International Index of Erectile Function (IIEF) questionnaire (11), two Sexual Encounter Profile (SEP) diary questions: "Were you able to insert your penis into your partner's vagina?" (SEP2) and "Did your erection last long enough for you to have successful intercourse?" (SEP3). Additional endpoints included IIEF domain scores that focussed on intercourse satisfaction, orgasmic function, sexual desire and overall satisfaction, additional diary questions (eg, satisfaction with erection hardness and overall satisfaction with sexual experience), and the Global Assessment Question (GAQ), "Has the treatment you have been taking over the past 4 weeks improved your erections?"

The Male Health Centres, Oakville, Ontario

Correspondence: Dr Richard W Casey, 407-1235 Trafalgar Road North, Oakville, Ontario L6H 3P1. Telephone 905-338-3130,

fax 905-338-3150, e-mail drcasey@malehealth.com 
TABLE 1

Efficacy of vardenafil in men with erectile dysfunction (broad population and harder-to-treat populations). Results of randomized, double-blind, fixed-dose, multicentre trials

\begin{tabular}{|c|c|c|c|c|c|}
\hline Efficacy variables & Duration/Parameter & Placebo & Vardenafil 5 mg & Vardenafil $10 \mathrm{mg}$ & Vardenafil $20 \mathrm{mg}$ \\
\hline \multicolumn{6}{|c|}{ Broad population study (6) } \\
\hline \multicolumn{6}{|l|}{ EF domain score } \\
\hline LOCF, n=170-195 & $12 / 26$ weeks & $15.0 / 14.8$ & $18.4^{*} / 17.8^{*}$ & $20.6^{*} / 21.2^{*}$ & $21.4^{*} / 21.8^{*}$ \\
\hline \multicolumn{6}{|l|}{ BL 12.5-13.6 } \\
\hline \multicolumn{6}{|c|}{ SEP3 - Overall mean success } \\
\hline rate per patient $(\%)$ & $12 / 26$ weeks & $32 / 33$ & $51^{*} / 52^{*}$ & $65^{*} / 65^{*}$ & $65^{*} / 67^{*}$ \\
\hline \multicolumn{6}{|c|}{$\mathrm{n}=171-194 \mathrm{BL} 14 \%-15 \%$} \\
\hline \multicolumn{6}{|l|}{ GAQ - \%, completers } \\
\hline $\mathrm{n}=91-169$ & $12 / 26$ weeks & $39 / 28$ & $65^{\star} / 65^{*}$ & $73^{*} / 80^{*}$ & $81^{*} / 85^{*}$ \\
\hline$\%$ of patients returning & $\mathrm{BL}-$ mild & 21 & 64 & 89 & 79 \\
\hline to normal erectile & $\mathrm{BL}-$ mild-mod & 17 & 44 & 55 & 47 \\
\hline function (LOCF at & $\mathrm{BL}-\bmod$ & 17 & 37 & 51 & 50 \\
\hline 12 weeks), $n=9-84$ & $\mathrm{BL}$ - severe & 4 & 14 & 26 & 40 \\
\hline
\end{tabular}

Diabetes population study $(9,12)$

EF domain score, mean

LOCF, $n=138-145$

12 weeks

12.6

NA

$17.1^{*}$

$19.0^{*}+$

BL 10.9-12.0

SEP3 - Overall mean success

rate per patien $\mathrm{t}(\%) \mathrm{n}=137-147$

12 weeks

23

NA

$49^{*}$

$54^{*}$

BL $9 \%-14 \%$

GAQ - \%, completers

$n=131-137$

12 weeks

13

NA

$57^{*}$

$72 * \dagger$

Post-NSRP population study (8)

EF domain score, mean

LOCF, $n=140-147$

12 weeks

9.2

NA

$15.3^{*}$

$15.3^{*}$

BL 9.1-9.3

SEP3 - Overall mean success

rate per patient (\%)

12 weeks

10

NA

$37^{*}$

$34^{*}$

$n=140-147$ BL 6\%-7\%

GAQ - \%, completers

$\mathrm{n}=131-137$ (bilateral NSRP)

12 weeks

$13(11)$

NA

$59(60)^{*}$

$65(71)^{\star}$

${ }^{*} P \leq 0.001$ versus placebo; ${ }^{\dagger} P<0.03$ versus vardenafil $10 \mathrm{mg}$. BL Baseline; EF Erectile function; GAQ Global Assessment Question; LOCF Last observation carried forward; NA Not applicable; NSRP Nerve-sparing radical prostatectomy; SEP-3 Sexual Encounter Profle question 3

Table 1 summarizes the efficacy results (IIEF-EF domain score, SEP3 and GAQ) with oral vardenafil in the broad ED patient population, as well as in patients with ED and diabetes and patients with ED post-NSRP. In these studies, the adverse event profiles were characteristic of PDE5 inhibitors, with the most frequent adverse events being transient headache, flushing, and rhinitis of mild-to-moderate intensity.

It is important to note that, in each of these studies, patients in the vardenafil-treated groups consistently reported improved intercourse satisfaction and orgasmic function, based on responses in the IIEF questionnaire. These patients also reported improved satisfaction with erection hardness and with the overall sexual experience (13-15).

Data from the North American and European pivotal trials conducted in the broad ED population were pooled and then examined to determine the therapeutic efficacy of vardenafil in various subpopulations with ED. These subgroups were defined based on a number of factors including etiology (organic/psychogenic/mixed), severity of ED at baseline and age $(16,17)$. Other categories included those who had specific comorbidities such as hypertension, hyperlipidemia and diabetes mellitus, and patients who were taking antihypertensive medications $(18,19)$. In each of these subpopulations, vardenafil significantly improved indices of erectile function compared with placebo, thereby providing evidence of efficacy in a broad range of men with ED.

In clinical practice, it is most likely that patients will be prescribed one dose of medication and then titrated up or down on an as-needed basis, according to tolerability and efficacy. This flexible-dose regimen was assessed in a 12-week, double-blind, placebo-controlled study in which patients were initially randomized to vardenafil $10 \mathrm{mg}$ or placebo, to be taken on demand (20). After four weeks and eight weeks, the vardenafil dose could be adjusted up to $20 \mathrm{mg}$ or down to $5 \mathrm{mg}$. The baseline average EF domain scores in this patient population $(n=309)$ indicated ED of moderate severity (12.6 for vardenafil and 13.1 for placebo). For all vardenafil-treated patients, the mean EF domain score at 12 weeks was significantly higher 
(22.9, last observation carried forward [LOCF]) compared wtih placebo $(14.6, \mathrm{LOCF})(\mathrm{P}<0.01)$. The results of the GAQ scores are presented in Table 2. For those patients who preferred to stay on the $10 \mathrm{mg}$ dose for the duration of the study, GAQ scores ranged from $92 \%$ to $100 \%$. For those preferring a $20 \mathrm{mg}$ dose, an additional improvement was seen at week 8 or week 12 . Final dosage choices were $3 \%$ for $5 \mathrm{mg}, 25 \%$ for 10 $\mathrm{mg}$ and $72 \%$ for $20 \mathrm{mg}$. Like other studies, the most common treatment-emergent adverse events were headache, flushing and rhinitis and were generally mild to moderate in intensity; discontinuations due to adverse events were low ( $3 \%$ for vardenafil and $2 \%$ for placebo).

\section{VARDENAFIL WORKS RAPIDLY}

The pharmacokinetic properties of a compound, ie, the time to reach sufficient concentrations in the blood that will lead to a therapeutic effect and the time to metabolize the active species, play a crucial role in the proper medical management of patients. With medications used to treat $\mathrm{ED}$, one must also consider the time element as it relates to the sexual encounter itself. An oral medication that is rapidly absorbed and has an associated fast onset of action could allow a couple to enjoy the element of spontaneity in their sexual activity. Vardenafil has a time to maximum plasma concentration of less than an hour and a half-life of 4 to $5 \mathrm{~h}$. To determine how this translates to the clinical level, the time elapsed after swallowing the pill until achieving an erection sufficient for sexual intercourse was measured in an at-home setting (21). In this large-scale, randomized, double-blind study, men with varying severities of ED were randomized to receive either vardenafil $20 \mathrm{mg}$ or placebo over a four week period. The earliest time among the first four doses that men perceived an erection adequate for penetration and intercourse was determined using a stopwatch. The outcome of the sexual encounter that followed was recorded in diaries. The primary variable was the earliest time that men perceived an erection adequate for penetration and intercourse. Secondary outcomes were time points for onset for SEP-2 and SEP-3 rates in men who had objective measures of success. No differences were observed between placebo and vardenafil for the primary efficacy variable. In addition, significant differences between placebo and vardenafil in SEP2 rates were not observed, although vardenafil rates were numerically higher than that of placebo. In those patients who perceived an erection that was confirmed by subsequent success in completing intercourse, a statistically significant greater proportion of men responded on vardenafil. At all predetermined timepoints from 16 to $25 \mathrm{~min}$, the response to vardenafil was statistically superior to placebo (at $16 \mathrm{~min}, 34 \%$ for vardenafil versus $24 \%$ for placebo, $\mathrm{P}=0.013$ ). At $25 \mathrm{~min}$, approximately half $(48 \%)$ of the men on vardenafil had at least one positive score for successful intercourse (SEP3) compared to only 30\% on placebo $(\mathrm{P}<0.0001)$. These results show that onset of action of vardenafil is recognized as early as $16 \mathrm{~min}$ after patients ingested the medication.

\section{IS RELIABILITY IMPORTANT?}

The importance of having a medication that is effective the first few times it is used, and continues to be effective over time, cannot be overstated as it relates to intimate relationships. Vardenafil has been shown to provide good reliability in terms of first time success and subsequent success rates for vaginal penetration (SEP2), successful completion of intercourse
TABLE 2

Efficacy of vardenafil versus placebo, given within flexible dose regimens, in patients with erectile dysfunction. Shown are percentages of patients responding yes to the question, "Has the treatment you have been taking over the past four weeks improved your erections?" at weeks 4, 8 and 12 (20)

\begin{tabular}{lcccc}
\hline Treatment & $\begin{array}{c}\text { Begin/End } \\
\mathbf{n}\end{array}$ & $\begin{array}{c}\text { Reported improvement in erections (\%) } \\
\text { Week 4 }\end{array}$ & Week 8 & Week 12 \\
\hline Placebo & $148 / 109$ & 21 & 36 & 36 \\
All vardenafil & $150 / 130$ & 80 & 83 & 86 \\
$10 / 10 / 10 \mathrm{mg}$ & $25 / 25$ & 96 & 100 & 92 \\
$\quad$ vardenafil & & & & \\
10/10/20 mg & $19 / 19$ & 100 & 85 & 100 \\
vardenafil & & & & \\
10/20/20 mg & $81 / 77$ & 70 & 83 & 82 \\
vardenafil & & & & \\
\hline
\end{tabular}

(SEP3) and overall patient satisfaction with the sexual experience. Retrospective analyses were conducted on data from the North American pivotal trial, and the North American and European pivotal trials, combined (22). In the analyses, evaluation was done for the first attempt and for subsequent perpatient attempts at intercourse up to week 12 . In the pooled data, the SEP-2 first-attempt $\rightarrow$ subsequent success rates were $76 \% \rightarrow 91 \%$ for vardenafil $20 \mathrm{mg}$, compared with $44 \% \rightarrow 74 \%$ for placebo. For SEP-3, first-attempt $\rightarrow$ subsequent success rates were $59 \% \rightarrow 84 \%$ for vardenafil $20 \mathrm{mg}$, compared with $25 \% \rightarrow 56 \%$ for placebo. Finally, for overall satisfaction with the sexual experience, first-attempt $\rightarrow$ subsequent success rates were $56 \% \rightarrow 79 \%$ for vardenafil $20 \mathrm{mg}$ compared with $19 \% \rightarrow 48 \%$ for placebo. These results, which are similar to those from the single study, show that vardenafil provides high reliability in key efficacy parameters important to patients in choosing and continuing oral treatment for ED.

A separate study spanning two years provides information on the long-term efficacy and tolerability of vardenafil (10). Following a four-week baseline period, 1020 men with ED of broad etiology and severity were randomized to $10 \mathrm{mg}$ or $20 \mathrm{mg}$ of vardenafil (fixed dose, double-blind) to be taken as needed for up to one year. Of 755 patients (74\%) completing the one year treatment period, 556 men continued to receive doubleblind medication for an additional year. The mean EF domain of the 479 patients (85\%) completing the study was 13.4 to 13.8 (moderate ED). Mean IIEF-EF domain scores reached levels considered as normal erectile function (at least 26) by week 8 and were sustained through week 104. Table 3 shows the results of the key efficacy parameters at baseline and at 104 weeks (LOCF).

Both the $10 \mathrm{mg}$ and $20 \mathrm{mg}$ doses of vardenafil were well tolerated, the majority of adverse events reported were mild to moderate and included rhinitis $(17 \% / 21 \%$ for $10 \mathrm{mg}$ and $20 \mathrm{mg}$, respectively), flushing (14\%/21\%), and headache $(18 \% / 20 \%)$. Adverse events led to premature discontinuation of a small percentage $(1 \% / 2 \%$ for $10 \mathrm{mg}$ and $20 \mathrm{mg}$, respectively) of patients.

As part of the overall apprehensions about reliability, lack of response to sildenafil is a major concern in the treatment of ED. To address this, a multinational, randomized, double-blind study was recently conducted to determine whether vardenafil was effective in patients who had a documented history of lack 
TABLE 3

IIEF-EF domain scores, mean per-patient success rates of penetration and successful completion of intercourse, and responses to the Global Assessment Question (GAQ).

Results of a double-blind, fixed-dose, two-year study (10)

\begin{tabular}{llcccc}
\hline Treatment & Time & IIEF-EF & SEP-2 & SEP-3 & GAQ \\
\hline Vardenafil 10 mg & $\mathrm{n}$ & 254 & 252 & 251 & 272 \\
& Baseline (\%) & 13.4 & 47.7 & 15.9 & \\
& Week 104 (\%) & 24.7 & 92.0 & 86.5 & 90 \\
Vardenafil 20 mg & $\mathrm{n}$ & 274 & 274 & 273 & 294 \\
& Baseline (\%) & 13.8 & 43.4 & 17.4 & \\
& Week 104 (\%) & 25.7 & 94.2 & 89.3 & 92
\end{tabular}

IIEF-EF International Index of Erectile Function-Erectile Function domain; SEP Sexual Encounter Profile

of response to sildenafil (23). The study was not designed to be a head-to-head comparison with sildenafil, but rather an investigation of the efficacy of vardenafil in this patient population, and therefore a sildenafil comparator arm was not included. There were six criteria used to define sildenafil nonresponders, and all six had to be met to include patients in this study. In this study, the flexible-dose regimen was again used to reflect the real-world experience. Patients were randomized to receive placebo or vardenafil $10 \mathrm{mg}$ for four weeks, with the option to stay on $10 \mathrm{mg}$, or titrate to $5 \mathrm{mg}$ or $20 \mathrm{mg}$ after each of two consecutive, four-week intervals (total of 12 weeks). Three primary endpoints were the IIEF-EF domain score, SEP2 and SEP3, and the GAQ was a secondary endpoint. As would be expected, mean baseline EF domain scores indicated a population with severe ED (9.3 to 9.7). With vardenafil, statistically significant and clinically meaningful improvements were seen in all the primary endpoints. There was a four-fold increase in successful intercourse completion rates over baseline, and EF domain scores were brought into the mild to moderate range. In addition, the GAQ scores where $62 \%$ for patients treated with vardenafil versus $15 \%$ on placebo $(\mathrm{P}<0.001)$. One of the major shortcomings of this study was the lack of a sildenafil comparator arm. There is significant evidence to suggest that sildenafil failures, when rechallenged, can often be converted to successes. The results of this study support the practice of rechallenging treatment failures with another PDE5 inhibitor.

\section{SAFETY}

Vardenafil has been shown to be generally well-tolerated in the 12-and 26-week trials, and also in the trials that last up to two years. The most frequently reported adverse events, such as headache and flushing, are typical of those in the PDE5 inhibitor class. Discontinuation rates due to adverse events are relatively small in the vardenafil-treated groups (3.4\%), compared with placebo (1.1\%). The cardiovascular safety profile of vardenafil has been analysed in the total patient population participating in five large-scale, placebo-controlled randomized trials $(\mathrm{n}=2605)$ and in smaller special population studies (24), such as in patients with coronary artery disease. Overall, the results from the pooled analysis indicate that vardenafil has a favourable cardiovascular safety profile. As expected from the mechanism of action of PDE5 inhibitors, small, transient decreases in blood pressure and increases in heart rate are observed with vardenafil relative to placebo, but the overall incidence of clinically significant changes in vital signs is very small. In addition, concomitant use of antihypertensive medications, overall or within the different classes, resulted in no or small incremental decreases in blood pressure that were generally similar in magnitude across the different classes. Cardiovascular adverse events were very few in the studies, and the incidence of these events were similar for patients receiving placebo or vardenafil.

In two double-blind, randomized studies, the effects of vardenafil $10 \mathrm{mg}$ and $20 \mathrm{mg}$ were assessed in men with stable coronary artery disease, undergoing an exercise stress test. In both studies, vardenafil did not impair the ability of men with stable coronary artery disease to exercise to a level similar to or greater than that associated with sexual intercourse $(25,26)$.

\section{CONCLUSION}

Vardenafil is a selective and potent PDE5 inhibitor that is highly effective in the treatment of ED in the majority of patients with mild to severe ED of varying etiology, including the more challenging patients with diabetes, post NSRP, or those patients who were considered to be sildenafil nonresponders by history. Vardenafil exhibits a rapid onset of action, an optimal window of responsiveness, and minimal interactions with food or alcohol, providing added benefits in terms of ease of use. Patients using vardenafil experienced high levels of first time success, which continued for the duration of the study periods. These features, together with proven reliability over time and a generally well-tolerated side effect profile of mostly mild and transient side effects, indicate that vardenafil should be considered as a first-line treatment option in men with $\mathrm{ED}$ who are suitable candidates for oral PDE5 inhibitor therapy.

ACKNOWLEDGEMENTS: The author would like to thank Dr Lynne de Souza and the medical/scientific publication groups at Bayer and GlaxoSmithKline who supplied current information on vardenafil.

\section{REFERENCES}

1. Hatzichristou D. Sildenafil citrate: Lessons learned from 3 years of clinical experience. Int J Impot Res 2002; 14(Suppl 1): S43-52.

2. Padma-Nathan H. A 4-year update on the safety of sildenafil citrate (Viagra). Urology 2002;60(Suppl 2):67-90.

3. Seftel AD. Challenges in oral therapy for erectile dysfunction. J Androl 2002;23:729-36.

4. Eardley I, Rosen R, Fisher W, Niederberger C, Sand M. Attitudes toward treatment of erectile dysfunction: Results from the MALES study. Eur Urol 2003;43(Suppl 2):97.

5. Porst H, Rosen R, Padma-Nathan H, et al. The efficacy and tolerability of vardenafil, a new, oral, selective phosphodiesterase type 5 inhibitor, in patients with erectile dysfunction: The first athome clinical trial. Int J Impot Res 2001;13:192-9.
6. Hellstrom W, Gittelman M, Karlin G, Thibonnier M, Padma-Nathan H. Vardenafil for treatment of men with erectile dysfunction: Efficacy and safety in a randomized, double-blind, placebo-controlled trial. J Androl 2002;23:763-71.

7. Hellstrom W, Gittelman M, Karlin G, et al on behalf of the Vardenafil Study Group. Sustained efficacy and tolerability of vardenafil, a highly potent selective phosphodiesterase type 5 inhibitor, in men with erectile dysfunction: Results of a randomized, double-blind, 26-week placebo-controlled pivotal trial. Urology 2003;61(Suppl 4A):8-14.

8. Brock G, Nehra A, Lipschultz L, et al. Safety and efficacy of vardenafil for the treatment of men with erectile dysfunction after radical retropubic prostatectomy. J Urol 2003;170:1278-83. 
9. Goldstein I, Young J, Fischer J, Bangerter K, Segerson T, Taylor T. Vardenafil, a new phosphodiesterase type 5 inhibitor, in the treatment of erectile dysfunction in men with diabetes: A multicenter double-blind placebo-controlled fixed-dose study. Diabetes Care 2003;26:777-83.

10. Stief C, Porst H, Saenz de Tejada I, Ulbrich E. Sustained efficacy and tolerability of vardenafil over two years in men with erectile dysfunction. Prog Urol 2003;13(Suppl 2):31.

11. Rosen R, Riley A, Wagner G, Osterloh I, Kirkpatrick J, Mishra A. The International Index of Erectile Function (IIEF): A multidimensional scale for assessment of erectile dysfunction. Urology 1997;49:822-30.

12. Yale J-F, Skamene A, Bailey G, and the Vardenafil Study Team. Long-term efficacy and safety of vardenafil in diabetic men with erectile dysfunction. Can J Diabetes 2002;26:310.

13. Donatucci C, Pommerville P, Niederberger C, Thibonnier M, McVary K, Hellstrom W. Vardenafil improved patient satisfaction with erection hardness, orgasmic function, and sexual experience in men with erectile dysfunction. J Urol 2003;169:246.

14. Vezina JG, Nehra A, Brock G, Pommerville P, Seger M, Padma-Nathan H. Vardenafil improved patient satisfaction with erection hardness, orgasmic function, and sexual experience in men with erectile dysfunction following nerve-sparing radical prostatectomy. J Urol 2003;169(No 4 Suppl):245.

15. Young J, Goldstein I, Fischer J, Segerson T, Taylor T. Vardenafil (Levitra ${ }^{\circledR}$ ) improved patient satisfaction with erectile hardness, orgasmic function and sexual experience in men with diabetes and erectile dysfunction. Diabetes 2003;52(Suppl 1):A16.

16. Donnatucci C, Eardley I, McVary KT, Thibonnier M. Vardenafil improves erectile function regardless of etiology or baseline severity in men with erectile dysfunction. J Urol 2002;167(Suppl):178.

17. Donnatucci C, Karlin G, Goldfischer E, Cohen S and Thibonnier $M$. Influence of age on the efficacy and safety of vardenafil, a novel phosphodiesterase- 5 inhibitor, for the treatment of erectile dysfunction. J Amer Ger Soc 2002;50(Suppl 4):S107.

18. Goldfischer E, Eardley I and Segerson T. Vardenafil improves erectile function in men with significant comorbidities associated with erectile dysfunction (ED). J Urol 2002;167(Suppl):178.
19. Padma-Nathan H, Porst H, Eardley I,Thibonnier M. Efficacy and safety of vardenafil, a selective phosphodiesterase 5 inhibitor, in men with erectile dysfunction on antihypertensive therapy. Am J Hypertens 2002;15:48A.

20. Hatzichristou D, Montorsi F, Porst H, Buvat J, Taylor T, Bandel T. A flexible dose regimen of vardenafil for erectile dysfunction: $A$ placebo-controlled trial. Eur Urol 2003;Suppl 2:176.

21. Padma-Nathan H, Kaufman J, Taylor T. Earliest time of onset of erections with vardenafil determined in an at-home setting. Prog Urol 2003;13(Suppl 2):31.

22. Montorsi F, Hellstrom W, Valiquette L, Eardley I, Homering H, Bandel T. Reliable efficacy over time of vardenafil, a potent, highly selective PDE-5 inhibitor in men with erectile dysfunction: A retrospective analysis of two pivotal phase III studies. Prog Urol 2003;13(Suppl 2):31.

23. Carson C, Hatzichristou D, Carrier S, Lording D, Young J, Murdoch M, for the Vardenafil Study Group. Vardenafil exhibits efficacy in men with erectile dysfunction unresponsive to prior sildenafil therapy: Results of a Phase III Clinical trial - Patient Response with Vardenafil in Sildenafil Nonresponders (PROVEN). Int J Impot Res 2003;15(Suppl 5):S175.

24. Kloner RA, Mohan P, Norenberg C, Pomerantz K, Segerson T, Glasser S. Cardiovascular safety of vardenfil, a potent, highly selective PDE5 inhibitor in patients with erectile dysfunction: An analysis of five placebo-controlled clinical trials. Pharmacotherapy 2002;22:1371.

25. Thadani U, Smith W, Nash S, et al. The effect of vardenafil, a potent and highly selective phosphodiesterase-5 inhibitor for the treatment of erectile dysfunction, on the cardiovascular response to exercise in patients with coronary artery disease. J Am Coll Cardiol 2002; $40: 2006-12$.

26. Thadani U, Chrysant S, Mazzu A, and the Vardenafil Study Group. The effect of vardenafil, a selective PDE5 inhibitor, on ischemic threshold, exercise tolerance, and circulatory responses during treadmill exercise in men with stable angina pectoris. J Am Coll Cardiol 2003;41:336A. 